\title{
Assessing direct flood damages using open data in diverse urban environments
}

\author{
Dominik Paprotny ${ }^{1 a}$, Kai Schröter ${ }^{1}$, Stefano Bagli², Attilio Castellarin ${ }^{3}$, Arthur H. Essenfelder ${ }^{4}$, Paolo Mazzoli², Luis Mediero ${ }^{5}$, \\ Oswaldo Morales-Napoles ${ }^{6}$, Jaroslav Mysiak ${ }^{4} \&$ Heidi Kreibich ${ }^{1}$. \\ ${ }^{1}$ GFZ German Research Centre for Geosciences, Section Hydrology, Telegrafenberg, 14473 Potsdam, Germany \\ ${ }^{2}$ GECOsistema, Piazza Malatesta 21, 47923 Rimini, Italy \\ ${ }^{3}$ University of Bologna, Department of Civil, Chemical, Environmental, and Materials Engineering, Viale del Risorgimento 2, 40136 Bologna, \\ Italy \\ ${ }^{4}$ Euro-Mediterranean Center on Climate Change, Ca' Foscari University of Venice, Via della Libertà 12, 30121 Venice, Italy \\ ${ }^{5}$ Universidad Politécnica de Madrid, Department of Civil Engineering: Hydraulic, Energy and Environmental, E.T.S.I. Caminos, Canales y \\ Puertos, Profesor Aranguren 3, 28040 Madrid, Spain \\ ${ }^{6}$ Delft University of Technology, Department of Hydraulic Engineering, Stevinweg 1, 2628CN Delft, the Netherlands.
}

\begin{abstract}
Local flood risk assessments require integration of many detailed data sources from the public and private sector. In the framework of the EIT Climate-KIC Demonstrator project "SaferPLACES", we explore how openly available datasets can be harnessed to both reanalyse past flood losses and estimate potential present and future flood damages. Three different cases studies were selected: Cologne in Germany, Rimini in Italy, and Pamplona in Spain. Each city has different size, economic structure and is subject to different types of flood events, namely fluvial, pluvial, and coastal. Here, we concentrate on methods for extracting exposure and predicting vulnerability for the residential and commercial sectors with openly available and crowd-sourced spatial datasets and public statistical data. Exposure is quantified at building level, covering residential and commercial assets. Further, vulnerability is calculated by Bayesian Network-based probabilistic models for residential and commercial sectors created on the basis of postdisaster household and company surveys. Finally, we use flood compensation data from a major flood in Pamplona in 2013 and analyse whether the cascade of models is able to recreate flood damages from a particular event. Flood risk estimates for Rimini are also shown to highlight the application of the project's model chain.
\end{abstract}

\section{Introduction}

Local flood risk assessments, particularly those made at the level of individual objects such as buildings (also known as "micro-scale"), require detailed information on hazard, exposure and vulnerability. Each component has its unique set of challenges. Hazard mapping needs to cover diverse flood types (fluvial, pluvial, coastal), involve high-resolution digital elevation models (DEM) together with data on flood protection (Amadio et al., 2019, Fuchs et al., 2019, Molinari et al., 2019). Exposure estimation includes identifying assets at risk, their characteristics and economic value (Merz et al., 2010). Finally, vulnerability (damage) modelling relies on integrating hazard and exposure data to derive the susceptibility of objects to incur losses from floods (Merz et al., 2004, Schröter et al., 2014). Maintaining accurate

${ }^{\mathrm{a}}$ Corresponding author: paprotny@gfz-potsdam.de

DOI 10.3311/FLOODRisk2020.9.1 flood damage estimates is further complicated by constantly evolving hazard (not only due to climate change, but also flood protection works, hydraulic interventions in the rivers and coasts, and increasing soil sealing) and exposure (growth in population, income and assets), which requires ever more up-to-date quantification (Paprotny et al., 2018).

EIT Climate-KIC Demonstrator project "Improved assessment of pluvial, fluvial and coastal flood hazards and risks in European cities as a mean to build safer and resilient communities" (SaferPLACES) aims to improve accuracy and availability of micro-scale flood risk maps in urban environments. The ongoing project particularly focuses on utilizing openly-available data sources, generating maps for both historical and future climate, and incorporating various mitigation and adaptation scenarios. Additionally, the model chain used to produce the maps 
will become available through a web interface, so that custom user-defined scenarios could be dynamically processed into flood risk maps.

The project has three case studies: Cologne in Germany, Rimini in Italy, and Pamplona in Spain. Those diverse cities are the primary testbed of the projects' hazard, exposure and damage models. All have sustained losses from fluvial and pluvial floods in recent years; Rimini was also affected by coastal floods. Consequently, the models developed in the project need to have a high degree of universality in order to correctly predict flood hazard and risk. Risk estimation covers residential and commercial assets, with the latter encompassing government-owned buildings as well, but excluding infrastructure and other non-building structures.

In this paper, we focus on exposure and damage modelling as the hazard computation methods are described by Samela et al. (2020). Also, while both direct and indirect losses are within the scope of the SaferPLACES project, this paper discusses only direct, tangible losses to assets. The main concepts of the methods applied in the project are shown in sections 2.1-2.3. Then, Rimini case study is described, presenting how specifically those methods were implemented (2.4). In section 2.5 the validation case study for the exposure and damage models is introduced. This leads to the results, which firstly highlight various hazard scenarios for Rimini (3.1), and then compare modelled and observed losses for the 2013 flood in Pamplona (3.2). The discussion compares the results from Pamplona with alternative damage functions and exposure estimates (4.1), and then covers the issues of data quality, limitations of the models and other uncertainties (4.2), followed by information on future research steps (4.3) before concluding (5).

\section{Materials and Methods}

\subsection{Hazard modelling}

Nowadays, the most used approach to model coastal, pluvial and fluvial hydraulics and to obtain detailed flood inundation maps is to make use of numerical hydrological and hydrodynamic models. Unfortunately, the practical application of these models is a resource intensive exercise, requiring large amounts of money, data and time. In particular detailed hydrologic-hydraulic numerical modelling is scarcely suitable for a consistent hazard assessment across large urban settlements and for supporting multiple mitigation and adaptation scenarios in cities. For this reason, in the framework of SaferPLACES we have developed three simplified and resource effective innovative DEM-based flood hazard assessment models tailored for urban areas, which are described in detail in Samela et al. (2020).

Firstly, Safer_RIVER is a model for mapping fluvial hazard which is based on the Geomorphic Flood Index (Samela et al., 2017). This approach may be particularly helpful about the preliminary flood hazard and risk assessment over large areas and in transboundary regions, or in ungauged basins. The analysis can be performed using data freely available online (nowadays several free
DEM sources exist, especially for research purposes), and is therefore economic and fast.

Secondly, Safer_RAIN identifies pluvial-flooded areas on the basis of nested surface depressions extracted from high-resolution DEMs (LIDAR); the volume of rainfall is accumulated in depressions and, as they are filled, water spills downstream to depressions located at lower elevations. The main simplifying assumptions are: (1) the drainage direction is identified according to the D8 method (O'Callaghan and Mark, 1984) and (2) overland flow dynamics is neglected and net rainfall volume accumulates into the nested depression system according to the capacity and hierarchical structure of depressions themselves. Safer_RAIN can use rainfall volumes that are either uniform or spatially variable (i.e. gridded). Spatially variable precipitation enables the user to: (1) simulate flooding resulting from weather radar products (hindcasts and nowcasts); (2) incorporate a simplified representation of stormwater drainage system capacity; (3) represent infiltration losses, since soil infiltration can deeply influence the inundation depth resulting from a pluvial flood event. As regards infiltration losses, a pixel-based adaptation of the event-based Green-Ampt infiltration model (Green and Ampt, 1911) is implemented in Safer_RAIN to represent these losses. In this way, the model can handle spatially variable net-precipitation, enabling users to promptly assess pluvial-flood hazard associated with different land-use and land-cover scenarios.

Finally, Safer_COAST is a DEM-based flood model with a simpler representation of the physical processes describing the coastal inundation by removing the time discretisation in the computation process. The model simulates the flow of water between neighbouring cells, a process known as region growing or region-based segmentation (Poulter and Halpin, 2008). The model is forced by the total volume of water associated with an extreme sea level scenario at a single or multiple location in the domain. From these points, the flood diffusion is simulated on a four-side or eight-side neighbours matrix using the following topological and physical rules: (1) neighbour cell is connected to the source of flooding; (2) the neighbour cell elevation is below the flood water height; (3) the volume of water in the source cell is enough to overflow the neighbour. There are several assumptions in such a simplified model: (1) infinite volume of water; (2) there is no infiltration into the soil; (3) the results represent the maximum theoretical flood extension after infinite time; and (4) water can only flow from one cell to another.

\subsection{Exposure modelling}

Modelling exposure involves identifying buildings in the area of interest, their function (residential or commercial by type of economic activity), their size, and their economic value in terms of replacement costs. The latter includes both the value of the building structure, but also household contents (for residential buildings) and machinery/equipment (for commercial buildings). The main source of building polygons and the information on 
their function is OpenStreetMap (OSM), a popular crowdsourced database. Economic value is assigned to buildings according to two sets of methodologies, separately for the residential and commercial sectors.

Methods for estimating exposure to residential assets was described comprehensively in Paprotny et al. (2020c). They contain two main elements: computing the useful floor space area of buildings, and multiplying this value by average gross replacement cost of the stock of buildings and household contents per $\mathrm{m}^{2}$ in a particular country and year. Floor space area is sometimes available from OSM, but it is very rarely based on direct evidence. Otherwise, this parameter has to be computed on the basis of building footprint and the number of floors or building height, if either of the two available; footprint areas can be computed from OSM building polygons. For Pamplona, the number of floors was available from an external dataset (see section 2.5), but no such data was available for Rimini or Cologne. Hence, a method was devised for estimating building height and transforming it into floor space.

Building heights from lidar scanning of 30 European capital cities were obtained from Copernicus Land Monitoring Service (2020a), intersected with residential buildings extracted from OpenStreetMap, and further merged with seven pan-European raster datasets from various providers. A non-parametric Bayesian Network (Hanea et al., 2006, 2015) was constructed, in which building height is predicted, after discarding less important variables, by three indicators: building footprint area (from OSM), population per $1 \mathrm{~km}^{2}$ (from GEOSTAT 2011 dataset by Eurostat 2020) and soil sealing per $100 \mathrm{~m}$ grid (from Imperviousness 2012 dataset by Copernicus Land Monitoring Service 2020b). The method was validated using several datasets, showing good potential for application in natural hazards damage modelling (Paprotny et al., 2020c). Using the three predictions, building height $(H)$ can be predicted at any location in Europe, and then converted into useful floor space area $(F)$ using building footprint area $(B)$ with the following empirical equation:

$$
F=0.7\left(\left\lfloor\frac{H-3.3}{2.4}\right\rfloor+1\right) B
$$

The useful floor space area (in $\mathrm{m}^{2}$ ) is the basis for computing building and household contents value. In Paprotny et al. (2020c), economic and demographic data were collected for 30 countries to compute the value of the national housing stock (taken from national accounts data directly or estimated using the perpetual inventory method) and national stock of consumer durables (calculated using the perpetual inventory method). Building and contents value per $\mathrm{m}^{2}$ was derived by dividing the national stock by the total floor space of dwellings in the country. In this way, average replacement costs of existing dwellings in the 30 countries was calculated, serving as a better basis of damage estimates than the construction cost of new dwellings often used in flood risk assessments (Huizinga et al., 2017). It should be noted that contents value excludes vehicles, as those are insured separately from other household durables and consequently distinguished from residential losses in flood loss datasets used for damage modelling and in the case studies. Data is available for years 2000-2017.
Commercial exposure estimation, described in Paprotny et al. (2020a), involves using OSM building footprints directly as the basis of calculating the economic value. Firstly, the various information on building function (including land use data) was standardized to the Global Earthquake Model (GEM) building taxonomy (Brzev et al., 2013) through the efforts of GFZ Section 2.6 (Seismic Hazard and Risk Dynamics), which were kindly shared for this study. Then, data on the national stock of relevant nonresidential assets (including both companies and governmental property), namely buildings other than dwellings, and machinery and equipment (excluding transport equipment) are collected per relevant economic activity sectors. Further, they are disaggregated to NUTS3 regions proportionately to gross value added generated by a given region. This stock of assets in a region is then distributed among OSM buildings proportionately to their footprint area through a table matching GEM building taxonomy to economic activities. Consequently, replacement cost of commercial assets is derived for eight different groups of buildings. The calculation is made for particular regions and years according to the requirements of each case study. It should be highlighted that all steps of the procedure, both for residential and commercial assets, involve only publicly-available datasets.

\subsection{Damage modelling}

Flood damage is computed separately for the residential and commercial sectors. However, both methodologies follow a similar framework. Both were prepared in the form of non-parametric Bayesian Networks (BN) containing seven nodes (variables). Two of those are relative losses to building structure and household contents (or machinery/equipment). The remainder are explanatory variables that would be collected for particular locations in order to predict the relative losses, which multiplied by exposure per building would generate the estimated flood damage. As BNs are probabilistic, they provide uncertainty bounds; they also can be used if some explanatory variables are not available. The limitation of the type of BNs used here is the necessity to use continuous variables; on the other hand, it relieves the need for discretizing variables which is a large source of inaccuracies in discrete $\mathrm{BN}$ models (Hanea et al., 2006). Both BNs are based on microdata from post-disaster household and company surveys, which provide information on the amount of sustained losses, exposure, flood intensity, use of precautionary and emergency measures, and various other characteristics of the households or companies and the building they are located in. In specific cases, the data are supplemented with external sources, such as river gauge records, hydraulic models and cadastral registers.

The residential $\mathrm{BN}$ damage model, described in detail in Paprotny et al. (2020b), was created using data from 11 flood events: six fluvial and three pluvial floods in Germany (2002-2014), 1993 Meuse river flood in the Netherlands and 2014 Secchia river flood in Italy. The German surveys followed a largely standardized questionnaire and were made for purely research purposes 
(Thieken et al., 2005, 2017). The Dutch and Italian datasets were made for the purpose of flood damage compensation to citizens and were complimented by hydraulic modelling of the respective events and merged with local building datasets (Wagenaar et al., 2017, Carisi et al., 2018). The final BN model contains the following explanatory variables: water depth, flow velocity, event return period, building usable floor space area and regional disposable income per capita. The model was tested in various configurations; the final model combines all complete (for variables in the BN) German and Italian data points and $40 \%$ of Dutch data points, as the 1993 Meuse flood dataset is far larger than for the other events. The model performed best for the German and Italian fluvial events, while mostly overestimated losses in the pluvial floods and the Dutch flood. As the model created only on the basis of fluvial and pluvial events, an independent case study of a coastal flood was carried out. It was found that the modelled losses were underestimated by $22 \%$ for two French departments most affected by the 2010 flood induced by Xynthia storm. However, they deviated from the average for the whole affected coast by only $2 \%$. Also, the residential $\mathrm{BN}$ model achieved better results than any of 10 alternative damage models for reproducing average losses for the 2010 flood.

The commercial BN damage model is explored in depth in Paprotny et al. (2020a). The model is based on five surveys carried out in Germany between 2003 and 2014. Those surveys followed a similar methodology to those performed for the residential sector (Thieken et al., 2017). Majority of the available data points refer to the 2002 and 2013 fluvial floods. Relative scarcity of continuous variables in the data was supplemented by various regional economic data from Eurostat (2020). Five economic activity sectors are distinguished in the data (agriculture, industry and different types of services), but in contrast to previous studies using this dataset (e.g. Sieg et al., 2017), all sectors are combined together into one model. The final model includes the following explanatory variables: water depth, inundation duration, precautionary measures indicator, regional gross value added per capita and regional gross fixed capital formation per person employed. The model performs best for the services sector, but rather overestimates losses in the industrial sector. Due to the limited variety of data included in the sample, three case studies were developed: 2010 coastal flood in France, 2013 Elbe flood in Saxony and 2014 Secchia river flood in Italy. For each area, the total amount of losses in the commercial sector was known. Modelled flood extents and water depths were collected, while exposure was computed as described in section 2.2. The results for the French case study were very similar to those for the residential sector, while for the other two losses were slightly overestimated (by $19 \%$ and $14 \%$ ). Still, the BN model achieved better results than most other alternative damage models that were tested.

\subsection{Rimini case study}

Rimini is an Italian city located by the Adriatic Sea in the province of the same name. Its population was
149,403 at the end of 2017 (Eurostat 2020). Recent floods include a pluvial flood in 2013 and a coastal flood in 2015, while no less than 21 floods affected the city between 1927 and 1997 (Consiglio Nazionale delle Ricerche, 2020). Here, we will present the coastal flood risk in Rimini based fully on the routines developed in the SaferPLACES project. Firstly, hazard maps with water depths were computed on the basis of a 1-meter resolution DEM (buildings included), as described in section 2.1. Maps were generated for three different return periods $(10,100$, $>100$ years) and three different sea level scenarios (present-day and sea level rise under RCP 4.5 emissions by 2050 and 2100). The extreme sea level scenarios were produced through the combination of historical extreme surge heights (Perini et al., 2017), sea level rise projections (Vousdoukas, 2017; 2018) and vertical land movement rates (Perini et al., 2017; Carbognin et al., 2009).

Additionally, all calculations were made for current topography and for an alternative flood-mitigation scenario. In the latter variant, the DEM is modified to include the alteration of the topography by a large seafront redevelopment project known as 'Parco Del Mare', which was approved for construction in 2019 (Comune di Rimini, 2019). In total, maps for 18 scenarios were generated.

OSM buildings were extracted for the whole province of Rimini, as it is the smallest unit for which regional economic data are available. However, the information on the occupancy of buildings has many gaps for that area, hence it had to be amended using land-use data from Urban Atlas 2012 were available, and from Corine Land Cover 2018 were not (Copernicus Land Monitoring Service, 2020a,b). For this purpose, a look-up table connecting the GEM building taxonomy with landuse classes was developed (Paprotny et al., 2020a). Additionally, OSM amenity data were used to correct function of some commercial buildings, especially to identify hotels and public buildings. Completeness of the building function data improved in the process from 34 to $85 \%$, measured by footprint area. The amended OSM building layer was used to estimate the value of nonresidential buildings with the methodology described in section 2.2 for year 2017, the latest available in terms of economic data. Floor space area of residential buildings was computed through estimation of building heights (section 2.2). It was then multiplied by standard exposure values per $\mathrm{m}^{2}$ for Italy in 2017 (Paprotny et al., 2020c). Residential and commercial exposure per $\mathrm{m}^{2}$ for Rimini is shown in Table 1.

Some variables were not available for damage modelling, namely flow velocity, inundation duration and precautionary measures indicator. However, this is not a problem for the BN model. Relevant economic variables were collected from Eurostat (2020) for 2017 and converted to 2015 prices as required by the model. 


\begin{tabular}{|l|r|r|r|r|}
\hline \multicolumn{1}{|c|}{ Region, year } & \multicolumn{2}{|c|}{ Rimini, 2017} & \multicolumn{2}{c|}{$\begin{array}{c}\text { Pamplona, } \\
2013\end{array}$} \\
\hline GEM code & \multicolumn{1}{c|}{ B } & \multicolumn{1}{c|}{ C/M } & \multicolumn{1}{c|}{ B } & \multicolumn{1}{c|}{ C/M } \\
\hline RES* & 1448 & 369 & 793 & 222 \\
\hline AGR* & 1616 & 379 & 180 & 48 \\
\hline ASS*, COM5 / 11 & 495 & 341 & 1223 & 272 \\
\hline COM1 / 2 / / 8 / 9 / 10 & 3628 & 1846 & 1309 & 730 \\
\hline COM3 & 2873 & 1108 & 701 & 735 \\
\hline COM4 / 6, EDU*, GOV* & 6893 & 1632 & 1738 & 852 \\
\hline COM99, MIX1 / & 3716 & 1423 & 1221 & 735 \\
\hline IND*, MIX4 / 6 & 437 & 652 & 952 & 762 \\
\hline MIX3 / 5 / 99 & 3077 & 1273 & 1121 & 745 \\
\hline
\end{tabular}

Table 1. Exposure per $\mathrm{m}^{2}$ of residential buildings (useful floor space area) and commercial buildings (building footprint area) according to Global Earthquake Model occupancy codes. * all codes in the group. $\mathrm{B}=$ buildings, $\mathrm{C} / \mathrm{M}=$ household contents (RES*) or machinery \& equipment (other).

\subsection{Pamplona 2013 flood case study}

Pamplona is a Spanish city in the region of Navarre with a population of 199,066 at the end of 2017 (Eurostat 2020). The city and the surrounding municipalities have been frequently affected, with no less than 38 floods recorded between 1913 and 2018 (Dirección General de Protección Civil 2020). Most floods are caused by the Arga river, which flows through Pamplona, driven by either heavy rainfall or snowmelt. Pluvial floods have also caused damages in this area.

In this study, we analyse losses from the 9 June 2013 flood event. Streamflow data for the hydrodynamic simulation of the event was supplied by the 'SAIH' realtime system of the Ebro River Basin Authority. The peak discharge for such an event in the city of Pamplona was $508 \mathrm{~m}^{3} / \mathrm{s}$. The IBER hydraulic model was used to estimate the spatial distribution of flow depth and velocity, as well as flood duration. It is a $2 \mathrm{D}$ hydrodynamic model that solves the depth-averaged shallow water equations (Bladé et al., 2014). The regional Government of Navarre supplied the observed flood extent of the 2013 event, which was used for validation of the model. Finally, the Spanish insurance organization 'Consorcio de Compensación de Seguros' (CSC) supplied a database of all direct flood damages covered by insurances in the Pamplona metropolitan area in the period 1996-2018. CSC covers all insurance compensations for natural hazards in Spain, hence the coverage of flood loss records is comprehensive. For details on the hydrodynamic simulation and Spanish flood loss data we refer to Mediero et al. (2020).

The analysis of losses was carried out for Pamplona and three other neighbouring municipalities with recorded losses during the 2013 flood: Burlada (population 18,934 as of 2017), Huarte $(7,014)$ and Villada $(10,150)$. The total number of compensated claims in those municipalities was 609 in the residential sector (excluding damages to vehicles) and 156 in the commercial sector (including 19 in industry). The value of compensation was 4.4 million euro for households and 7.2 million euro for companies (including 3.2 million in industry).

To compute exposure during the 2013 event, the OSM building layer was first obtained for the Navarre region, however it was found to be highly incomplete both for the study region and the affected area, and the geometry of buildings often inaccurate. To reduce this source of uncertainty in the validation of the damage model, another building layer was therefore obtained from the cadastral register maintained by the Regional Government of Navarre. This resource provided comprehensive coverage of buildings in the region, together with information on the number of floors. However, the information on building function was only accessible at the level of parcels, considering 25 categories. Consequently, the building occupancy was derived using four datasets in the following order: OpenStreetMap, the regional cadastre (for Pamplona and surrounding areas only), Urban Atlas 2012 (for the metropolitan region of Pamplona only) and Corine Land Cover 2012. In this way, function was assigned to $84 \%$ of buildings measured by footprint area.

Information on the number of floors was used directly to estimate floor space area of residential buildings. Residential and commercial exposure per $\mathrm{m}^{2}$ for Pamplona in 2013 was computed as for Rimini, though the residential exposure was revised compared to Paprotny et al. (2020) due to availability of new, improved economic data for Spain (Table 1). Economic variables were collected from Eurostat (2020) for year 2013 and converted to 2015 price level. The only missing variable is the precautionary measures indicator, as in contrast to the other case study we obtained information on all flood intensity variables.

\section{Results}

\subsection{Flood risk in Rimini}

Rimini consists of almost 24,000 buildings, which we estimate are worth about 21 billion euro, with household contents, machinery and equipment worth further 6 billion euro. The hazard maps indicate that large parts of the city could be affected by coastal flooding. The 'Parco del Mare' project would protect some densely populated districts in the city centre, as visible in Figure 1. 


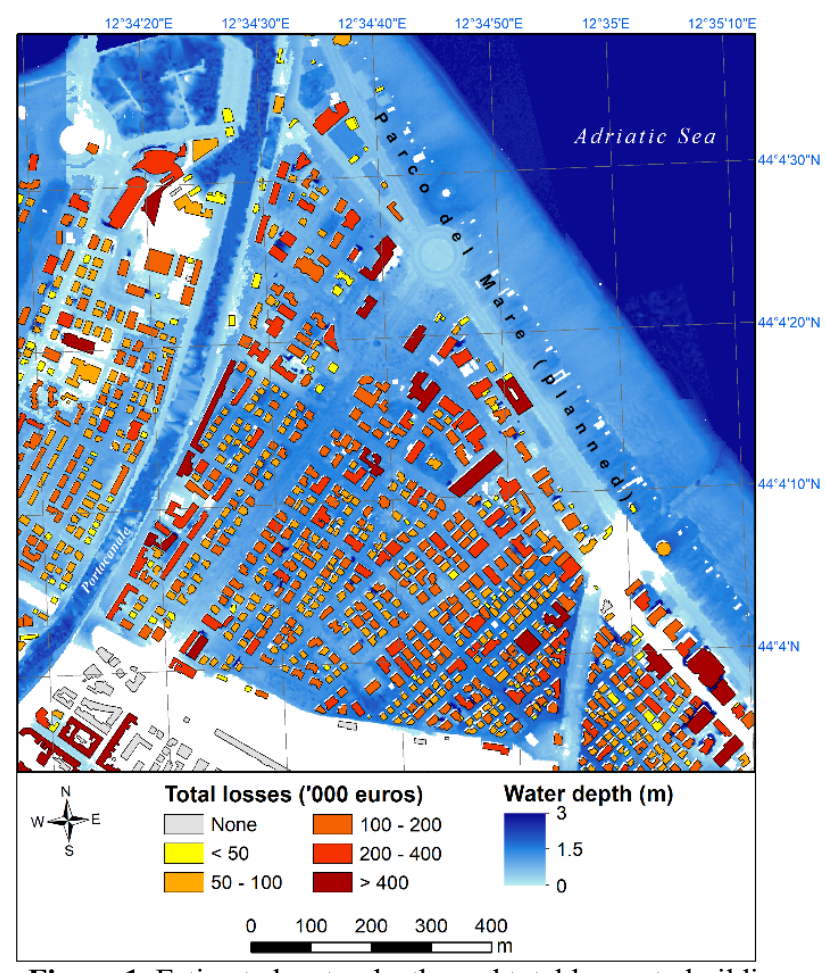

Figure 1. Estimated water depths and total losses to buildings and their contents as a result of a 100-year coastal flood in a fragment of Rimini.

Almost 3400 buildings are at risk of flooding under the most extreme flood scenario (Figure 2), including 16\% of residential and $8 \%$ of commercial buildings. However, the highest share of buildings is located at present in the hazard zone with the lowest probability of occurrence ( $<1 \%$ per annum). Under sea level rise, this would change significantly, as by 2100 most endangered buildings would be in the 10-100 years flood zone. The 'Parco del Mare' project would reduce the impact of floods for the most extreme scenario by $47 \%$, but would have no impact on the losses from more frequent events, because they involve an area of the city which is not protected by the planned barrier. In the medium term it would be very effective against floods intensified by sea level rise, reducing losses by $52-68 \%$, while in the long-term it would mitigate flood risk for floods only with a return period of up to 100 years (i.e., by 2100).

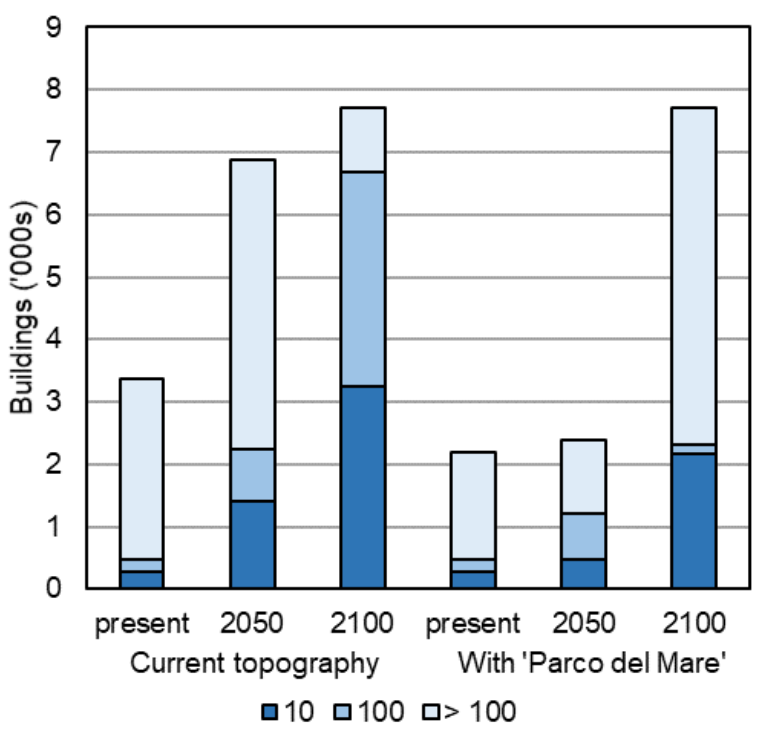

Figure 2. Buildings in the coastal flood hazard zones by return period, under present or future climate (2050, 2100 RCP 4.5),

with and without alterations expected under the 'Parco del Mare' project.

Majority of the losses would be borne by the residential sector in case of a flood. The share of residential buildings located in the hazard zones is higher than for commercial buildings, though the latter would sustain higher average loss. Still, the residential sector would be responsible for $72-87 \%$ of losses depending on the scenario. Currently, almost 270 million euro would be lost under the most extreme flood scenario, doubling by 2050 and tripling by 2100 (Figure 3). Under less extreme scenarios, the losses are much smaller, but would increase by a much higher multiplier in the future. Residential buildings would benefit greatly from the 'Parco del Mare' redevelopment, as estimated losses would decrease for the most extreme flood scenario by $51 \%$ at present and $70 \%$ under 2050 sea level rise. Most of the losses to the residential assets would stem from damages to the building structure, with only small variation between scenarios of the share $(59-63 \%)$. 


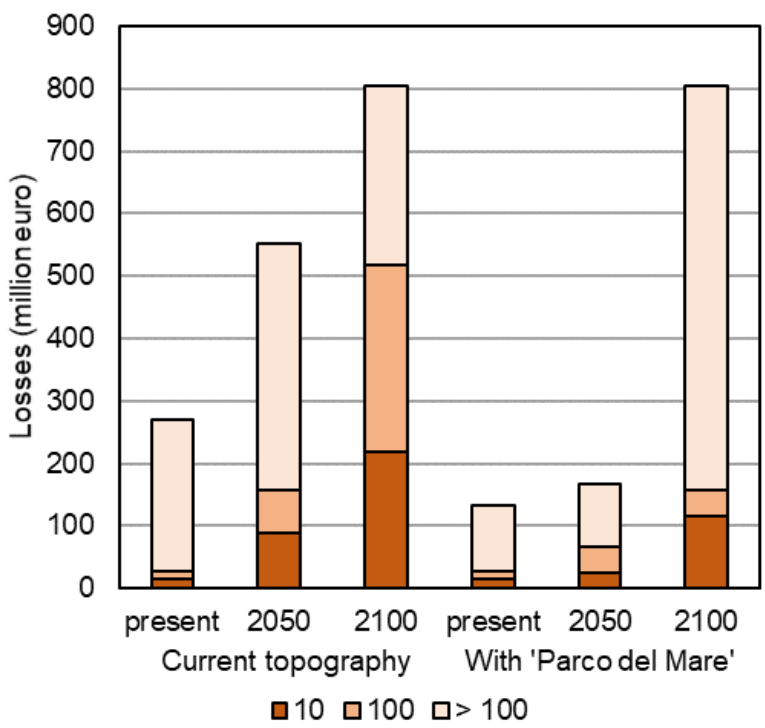

Figure 3. Estimates losses in the residential sector resulting from different flood event scenarios (see Figure 2).

Coastal flood hazard in Rimini is rather limited to the residential districts, as losses to commercial assets would be up to four times lower than in the residential sector (Figure 4). They are also more evenly distributed between hazard zones. On the other hand, the growth in losses under sea level rise is projected to be stronger. Furthermore, commercial establishments would benefit less from 'Parco del Mare', as the losses would be reduced only by $30 \%$ in the historical extreme scenario, and $43 \%$ in 2050. Detailed breakdown of losses by economic activity is affected by limited occupancy data, though some observations could be made. Losses to schools constitute a large share, far higher than their share in commercial assets in the city, but they would decline more due to the 'Parco del Mare' project than most other categories. Buildings for sports and recreation, as well as those related to transportation and storage, are also a source of a disproportionately large share in losses, while industrial or agricultural buildings are almost entirely located outside the hazard zones. Losses to building structure and machinery/equipment are roughly equal, though in the less extreme floods the movable assets show higher losses. Overall, the share of building structure in total commercial loss is estimated at $42-56 \%$ depending on the scenario.

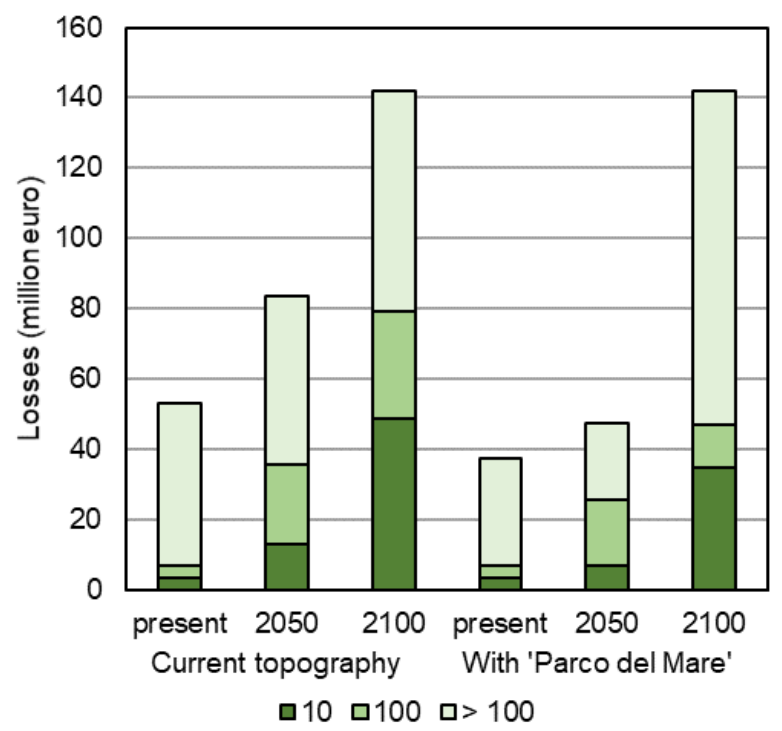

Figure 4. Estimates losses in the commercial sector resulting from different flood event scenarios (see Figure 2).

\subsection{Losses in Pamplona, 2013}

Our reconstruction of the 2013 flood has identified 383 flooded buildings, including 225 residential ones. Many establishments related to sports, recreation and agriculture were shown as inundated in the city and its surroundings (Figure 5).

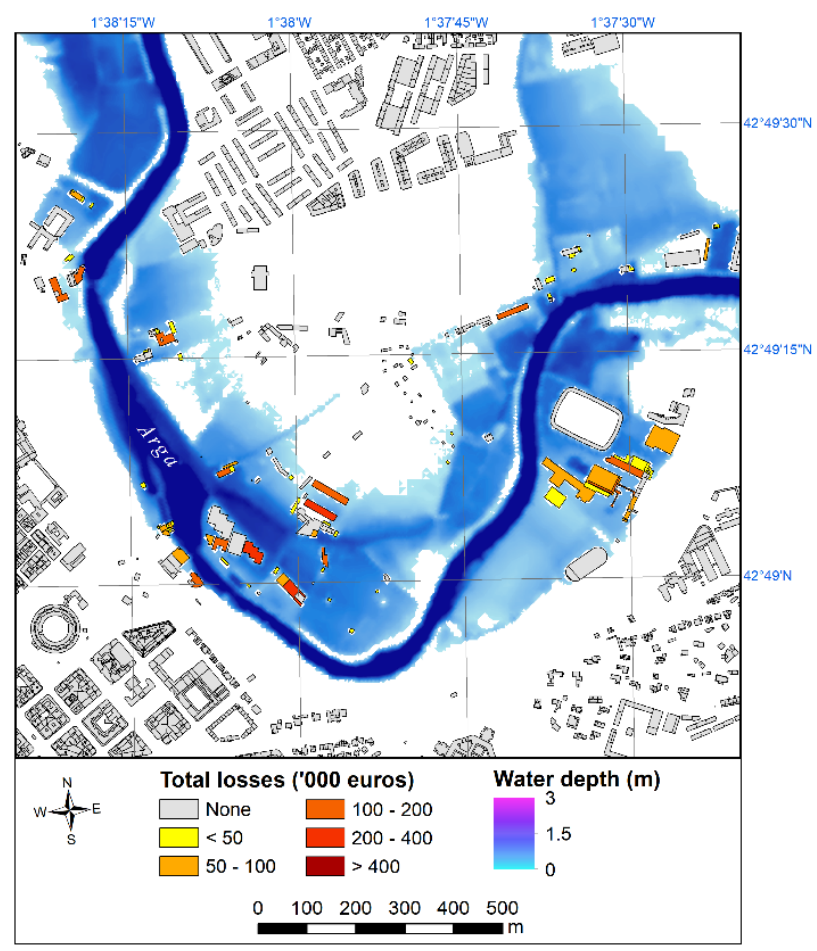

Figure 5. Estimated water depths and total losses to buildings and their contents as a result of the June 2013 flood in a fragment of Pamplona.

The number of residential buildings was smaller than the number of compensations, but most buildings contained multiple households. Based on footprint area buildings and the average size of households in Spanish cities in 2012 of $90 \mathrm{~m}^{2}$ (Eurostat 2020), the number of 
households on the ground floor would be 545. (No water depths above the typical first floor level was recorded at the intersection with building polygons). As a result, the average loss per household was estimated in our analysis to be slightly above 9000 euro, which is $23 \%$ more than observed. Still, the observed value falls within the $95 \%$ confidence interval of the model (Table 2), and also in a narrower $80 \%$ interval.

\begin{tabular}{|c|c|c|}
\hline \multirow{2}{*}{ Measure } & \multicolumn{2}{|c|}{ Sector } \\
\hline & Residential & Commercial \\
\hline \multicolumn{3}{|l|}{ Observations } \\
\hline $\begin{array}{l}\text { Affected households/ } \\
\text { companies (no.) }\end{array}$ & 609 & 156 \\
\hline $\begin{array}{l}\text { Total observed losses (million } \\
\text { euro) }\end{array}$ & 4.45 & 7.32 \\
\hline $\begin{array}{l}\text { Average loss per household/ } \\
\text { company (euro) }\end{array}$ & 7305 & 46,358 \\
\hline \multicolumn{3}{|l|}{ Model } \\
\hline $\begin{array}{l}\text { Buildings identified as } \\
\text { flooded (no.) }\end{array}$ & $174 *$ & 158 \\
\hline $\begin{array}{l}\text { Total modelled losses } \\
\text { (million euro) }\end{array}$ & $\begin{array}{r}4.92 \\
{[3.5-7.1]}\end{array}$ & $\begin{array}{r}9.64 \\
{[7.6-14.8]}\end{array}$ \\
\hline $\begin{array}{l}\text { Average loss per household/ } \\
\text { company (euro) }\end{array}$ & $\begin{array}{r}9020 \\
{[6438-} \\
13,083] \\
\end{array}$ & $\begin{array}{r}61,044 \\
{[48,012-} \\
93,574] \\
\end{array}$ \\
\hline $\begin{array}{l}\text { Difference between modelled } \\
\text { and observed loss per } \\
\text { household/company (\%) }\end{array}$ & $\begin{array}{r}+23 \% \\
{[-12 \%-} \\
+79 \%] \\
\end{array}$ & $\begin{array}{l}+32 \% \\
{[-8 \%-} \\
+79 \%]\end{array}$ \\
\hline
\end{tabular}

Table 2. Main validation results for the Pamplona case study. Values in brackets are the $95 \%$ confidence interval of the predictions. * containing estimated 545 households on the ground floor.

The number of commercial buildings was, in contrast to residential ones, larger than the number of claims (211 vs 156), but not all buildings were considered. Given that some buildings might contain many companies, or multiple buildings could belong to the same company, the sample was reduced to match the number of claims by removing an equal number of small and large buildings, measured by footprint area. Assuming, very roughly, that each remaining building represented one company, the average loss would be 61,044 euro, which is $32 \%$ more than observed. The observed loss is within the $95 \%$ confidence intervals of the model, but outside the $80 \%$ interval. The results are less accurate for the two subcategories of companies. Average losses in the industry sector are underestimated by $48 \%$, though the very small number of data points (both observed claims and modelled losses) creates very wide uncertainty bounds. Average losses to the remaining establishments, mostly services, are overestimated by $85 \%$, and the $95 \%$ confidence interval does not cover the observed value.

\section{Discussion}

\subsection{Comparison with other approaches}

The overall results for the Pamplona case study require further evaluation to distinguish the effect of exposure and vulnerability modelling on total losses, as error from both might negate each other, leading to a spuriously accurate result. This is also necessary due to uncertainty with computing the average modelled loss to match the definition of a claim in the insurance data. Consequently, we compare our results with a set of alternative damage models. Additionally, we recalculate the exposure in monetary terms using data from Huizinga et al. (2017), referred to here as "JRC exposure", in order to analyse the effect on damage models' results compared with the "GFZ exposure" estimates from Paprotny et al. (2020a,c).

In the residential sector, only the ICPR damage curve achieved a better result than the BN model used in this study (Figure 6). One model (MURL) underestimated losses very significantly, while seven other models strongly overestimated them. With JRC exposure, the values grow noticeably, especially due to almost three times higher contents value estimates.

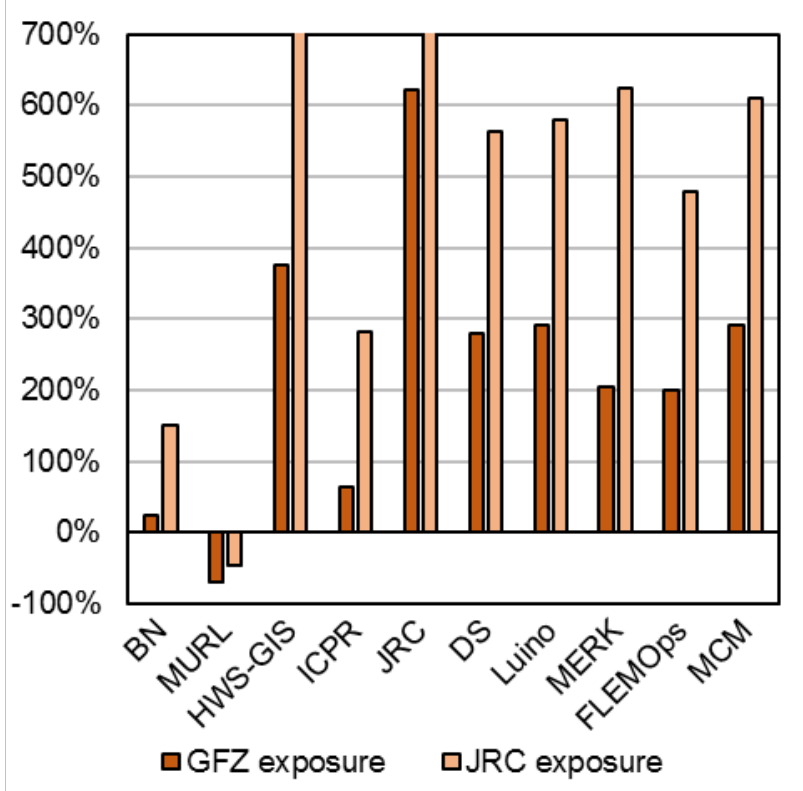

Figure 6. Difference between modelled and observed average losses in the residential sector from the 2013 flood in Pamplona, for 10 damage models and two exposure valuations.

Some of the damage models provide estimation for the commercial sector as well. Only one model provided a better estimate of losses from the 2013 event compared to our BN model, the Dutch damage curves 'Standaardmethode 2004' (SM) from Kok et al. (2005). All models for the commercial sector show higher damages under JRC exposure estimates, with two models performing better as a result. Looking at the sectoral split of companies, all models except for MERK (Reese et al., 2003) strongly underestimated losses for industrial companies, and most overestimated them for other types of companies. 


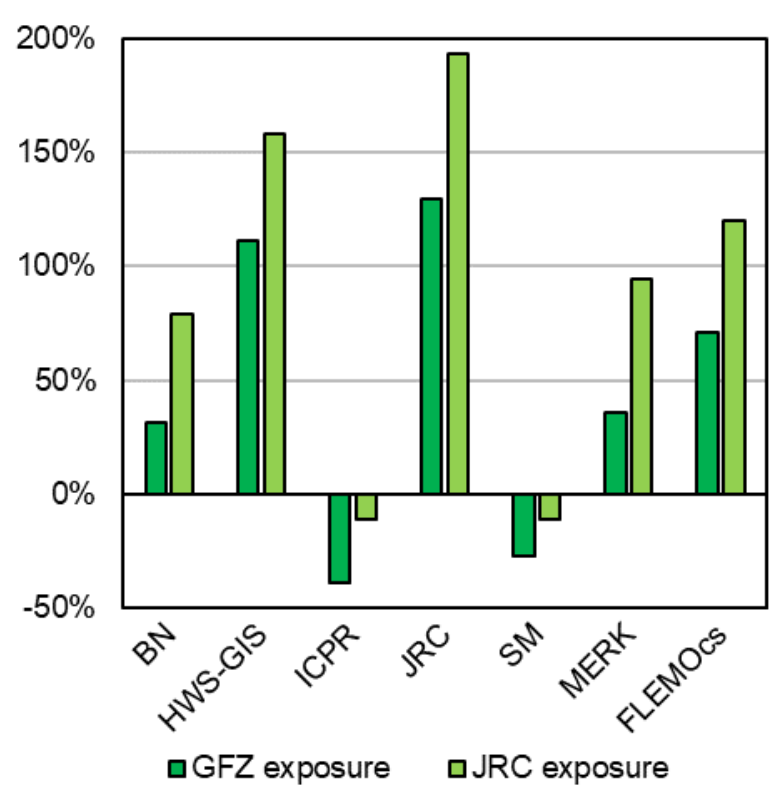

Figure 7. Difference between modelled and observed average losses in the commercial sector from the 2013 flood in Pamplona, for 7 damage models and two exposure valuations.

\subsection{Limitations and uncertainty}

A chain of models for computing flood risk inevitably includes simplifications and sometimes considerable uncertainties at various steps of the process. In the first stage, accurate computation of the flood intensity and its extent is needed to correctly estimate the hazard. For example, pluvial and coastal flood hazard assessment has been computed with DEM-based models (Safer_COAST and Safer_RAIN) able to quickly simulate water inundation depth for a specific extreme sea level of interest. This approach provides results much faster compared to hydrodynamic and hydraulic ones, being suitable for probabilistic and real-time flood risk assessment. As a downside, it cannot provide hazard information such as flow velocity or duration, and it is not able to simulate the overtopping of water over obstacles and the temporal dynamic of the events.

The 2D hydrodynamic modelling employed for Pamplona provides better estimation of the flood dynamic. But some uncertainties still arise from a set of sources. First, streamflow estimates from water levels recorded at gauging stations lead to errors in flood hydrographs used as input in the hydraulic model. Second, roughness coefficient values in the reach and overbanks were estimated from land use layers. Third, epistemic uncertainties associated with errors in model outputs, as the model cannot simulate perfectly the real hydraulic behaviour of water in a river. However, such uncertainties were reduced through the model calibration.

The exposure component has two main sources of uncertainty: the buildings layer and the valuation of assets. OpenStreetMap is very uneven in completeness, precision of buildings' geometry and occupancy, and timeliness. In some countries, OSM integrates administrative sources on buildings or has a particularly vibrant user community, resulting e.g. in highly accurate data for Cologne. However, despite the building geometries being complete for Rimini, occupancy data was very limited, requiring us to approximate the function of buildings using land use data. In the case of Pamplona, OSM data was very incomplete - only 100 buildings were identified in the estimated flood zone of the 2013 event, while using local administration's data identified more than 800 . Still, even if buildings and their occupancy is complete, the major issue is representing correctly many instances of mixed residential and commercial. Since many residential buildings have services located on the ground floor, flood loss might primarily stem from inundation of those commercial premises, even if most assets in the building are residential. Information on shops and amenities could be gathered from OSM, but this leaves large uncertainty on what is the size of premises of a particular establishment.

Economic value of residential buildings and household contents is assigned based on country-wide estimates based on national accounts data, which may not be representative for the characteristics of buildings in a particular area that is predominantly urban due to different technologies and age of buildings, as well as size of dwellings. As the estimate refers to the existing stocks of buildings, present-day variation in construction costs within the country is less relevant. Local income levels (compared with national average) could affect the accuracy of estimates of contents value. In the commercial sector, we compute the asset value by disaggregating national assets to regions, and then according to the footprint area of particular types of buildings. Apart from the uncertainty of connecting sectors of economic activity to particular types of buildings, the use of footprint area ignores the possible variations in building height. This information is rarely available from OSM and affects both residential and commercial asset estimation.

The damage model has several limitations. While the residential damage model is based on a diversified sample of fluvial and pluvial events from different countries, the commercial loss model is based only on German survey data, which might have limited transferability. Still, the validation for Pamplona has shown encouraging results, as did previous validation for 2010 coastal flood in France (Paprotny et al. 2020a,b), even if made without using all nodes of the BN due to lack of certain data. The method itself, utilizing non-parametric Bayesian Network, is subject to potential inaccuracies due to the use of a Gaussian copula as the dependency model. This assumption could be tested variously, e.g. using the dcalibration score proposed by Morales-Nápoles et al. (2014). For both models, the determinant of the empirical rank correlation matrix falls within the $90 \%$ confidence interval of the determinant of the empirical normal distribution. However, the determinant of the BN's rank correlation matrix is outside the $90 \%$ confidence interval of the determinant of the random normal distribution sampled for the same correlation matrix. This means that while the joint normal copula is valid for the variables in the model in general, but is not valid for the particular configuration of the BN, suggesting that more arcs should be added to the model. However, with the BN models we wanted to avoid spurious connections between nodes, i.e. those that cannot be theoretically explained. 
Last but not least, the use of aggregated flood loss data for Pamplona creates considerable uncertainty when making the comparison between model output and observations. The loss data are for households and companies, while exposure data can provide only direct information on buildings, which might contain many households and companies. This creates difficulty in ascertaining whether only the actually affected households and companies were identified and in what percentage, hence the error of the tested models could be higher or lower in reality than calculated with the best available information.

\subsection{Future outlook}

The damage modelling framework described in this paper will be in due course applied to the three cities selected as case studies (Cologne, Pamplona and Rimini) and cover all types of flood hazards that affect each city. An important feature of the work is the use of open data. As was presented in this paper, the exposure layer could be computed only utilizing open resources such as OpenStreetMap and other publicly-available datasets. The parameters for the damage model also do not require any closed datasets to be used. The BN models are quantified with data not available for dissemination, partially due to privacy protection of household- or company-level microdata. However, the damage model code can be published in a format that would not conflict with the need for protecting survey data, and it is planned to do so in the future.

The models and outputs for the case studies will be available online also through a web demonstrator, which will allow the user to run the damage model for different hazard scenarios, including various flood mitigation scenarios. Such flexibility will foster better understanding of flood hazard and risk under present and future climate.

\section{Conclusions}

This paper has presented the damage modelling framework of EIT Climate-KIC Demonstrator project "SaferPLACES", showing both the potential and some pitfalls of using open data for this purpose. Availability of crowd-sourced building data as well as public panEuropean geographical and statistical datasets enables estimating local exposure, but the uneven quality of the building layer requires careful evaluation of its suitability in each area.

The full modelling procedure was highlighted with the case study of Rimini. Our calculations show high damage potential from coastal flood events, and large growth in possible damages under sea level rise for relatively frequent events (return period up to 10 years). However, the planned seafront redevelopment project "Parco del Mare" would strongly reduce those risks, especially for the residential sector, in the medium term (up to year 2050). More work would be necessary to adapt to long-term sea level risk (up to year 2100 under RCP 4.5).
Apart from validation shown in studies dedicated to particular elements of the modelling chain, we introduce here another test of the residential and commercial damage models, using aggregated insurance compensation data from the 2013 flood in Pamplona. Notwithstanding the large uncertainty on the occupancy of buildings and the method of comparison with insurance data, the model outputs have shown close alignment with average observed losses. Better results were also achieved compared to almost all alternative exposure and damage models tested.

\section{Acknowledgments}

This work was supported by Climate-KIC through project "SAFERPLACES - Improved assessment of pluvial, fluvial and coastal flood hazards and risks in European cities as a mean to build safer and resilient communities", Task ID TC2018B 4.7.3-SAFERPL_P430-1A KAVA2 4.7.3. Further funding was received from the European Union's Horizon 2020 research and innovation programme under grant agreement no. 730381. The authors would like to thank Danijel Schorlemmer and Thomas Beutin for adapting OSM data to the GEM building taxonomy and technical discussions.

\section{References}

1. Amadio, M., A. R. Scorzini, F. Carisi, A. H. Essenfelder, A. Domeneghetti, J. Mysiak and A. Castellarin (2019). Testing empirical and synthetic flood damage models: the case of Italy. Natural Hazards and Earth System Sciences 19, 661-678.

2. Bladé, E., L. Cea, G. Corestein, E. Escolano, J. Puertas, E. Vázquez-Cendón, J. Dolz and A. Coll (2014). Iber: herramienta de simulación numérica del flujo en ríos. Revista Internacional de Métodos Numéricos para Cálculo y Diseño en Ingeniería 30(1): 1-10.

3. Brzev, S., C. Scawthorn, A. W. Charleson, L. Allen, M. Greene, K. Jaiswal and V. Silva (2013). GEM Building Taxonomy Version 2.0, GEM Technical Report 2013-02, Pavia, Italy.

4. Carbognin, L., P. Teatini and L. Tosi (2009). The impact of relative sea level rise on the Northern Adriatic Sea coast, Italy. WIT Transactions on Ecology and the Environment 127: 137-148.

5. Carisi, F., K. Schröter, A. Domeneghetti, H. Kreibich, A. Castellarin (2018). Development and assessment of uni- and multivariable flood loss models for Emilia-Romagna (Italy). Natural Hazards and Earth System Sciences 18: 2057-2079.

6. Consiglio Nazionale delle Ricerche (2020). Sistema Informativo sulle Catastrofi Idrogeologiche.

7. Copernicus Land Monitoring Service (2020a). Urban Atlas.

8. Copernicus Land Monitoring Service (2020b). PanEuropean.

9. Dirección General de Protección Civil y Emergencias (2020). Catálogo Nacional de Inundaciones Históricas. 
10. Eurostat (2020). Eurostat.

11. Fuchs, S., M. Keiler, R. Ortlepp, R. Schinke and M. Papathoma-Köhle (2019). Recent advances in vulnerability assessment for the built environment exposed to torrential hazards: Challenges and the way forward. Journal of Hydrology 575, 587-595.

12. Green, W. R. and G. A. Ampt (1911). Studies on soil physics-1. The flow of air and water through soils. The Journal of Agricultural Science 4(1): 1-24.

13. Hanea, A. M., D. Kurowicka and R. M. Cooke (2006). Hybrid Method for Quantifying and Analyzing Bayesian Belief Nets. Quality and Reliability Engineering International 22: 709-729.

14. Hanea, A., O. Morales Nápoles and D. Ababei (2015). Non-parametric Bayesian networks: Improving theory and reviewing applications. Reliability Engineering \& System Safety 144: 265284.

15. Huizinga, J., H. de Moel and W. Szewczyk (2017). Global flood depth-damage functions. Methodology and the database with guidelines, EUR 28552 EN, Luxembourg.

16. Kok, M., H. Huizinga, A. Vrouwenvelder and A. Barendregt (2005). Standaardmethode2004 - Schade en Slachtoffers als gevolg van overstromingen. DWW-2005-005, RWS Dienst Weg- en Waterbouwkunde.

17. Mediero, L., L. Garrote, D. Santillán, L. CuetoFelgueroso and E. Soriano (2020). Flood depthdamage curve estimates in the Pamplona metropolitan area (Spain). 4th European Conference on Flood Risk Management, Budapest, Hungary, submitted.

18. Merz, B., H. Kreibich, A. Thieken and R. Schmidtke (2004). Estimation uncertainty of direct monetary flood damage to buildings. Natural Hazards Earth System Sciences 4: 153-163.

19. Merz, B., H. Kreibich, R. Schwarze and A. Thieken (2010). Review article "Assessment of economic flood damage". Natural Hazards Earth System Sciences 10: 1697-1724.

20. Molinari, D., K. M. de Bruijn, J. T. CastilloRodríguez, G. T. Aronica and L. M. Bouwer (2019). Validation of flood risk models: Current practice and possible improvements. International Journal of Disaster Risk Reduction 33, 441-448.

21. Morales Nápoles, O., A. M. Hanea, and D. T. H. Worm (2014). Experimental results about the assessments of conditional rank correlations by experts: example with air pollution estimates. In: Steenbergen RDJM, Van Gelder PHAJM, Miraglia S, Vrouwenvelder ACWM (Eds.), Safety, Reliability and Risk Analysis: Beyond the Horizon, Taylor \& Francis, London, pp. 1359-1366.

22. O'Callaghan, J. F. and D. M. Mark (1984). The extraction of drainage networks from digital elevation data. Computer Vision, Graphics, and Image Processing 28(3): 323-344.

23. Paprotny, D., A. Sebastian, O. Morales Nápoles and S. N. Jonkman (2018). Trends in flood losses in Europe over the past 150 years. Nature Communications 9: 1985.
24. Paprotny, D., H. Kreibich, O. Morales Nápoles, A. Castellarin, F. Carisi and K. Schröter (2020a). Exposure and vulnerability estimation for modelling flood losses to commercial assets in Europe. Science of the Total Environment 737: 140011.

25. Paprotny, D., H. Kreibich, O. Morales Nápoles, D. Wagenaar, A. Castellarin, F. Carisi, X. Bertin, B. Merz and K. Schröter (2020b). A probabilistic approach to estimating residential losses from different flood types. Natural Hazards, in review.

26. Paprotny, D., H. Kreibich, O. Morales Nápoles, P. Terefenko and K. Schröter (2020c) Estimating exposure of residential assets to natural hazards in Europe using open data. Natural Hazards and Earth System Sciences 20: 323-343.

27. Perini, L., L. Calabrese, P. Luciani, M. Olivieri, G. Galassi and G. Spada (2017) Sea-level rise along the Emilia-Romagna coast (Northern Italy) in 2100: Scenarios and impacts. Natural Hazards and Earth System Sciences 17: 2271-2287.

28. Poulter, B. and P. N. Halpin (2008). Raster modelling of coastal flooding from sea-level rise. International Journal of Geographical Information Science 22: 167-182.

29. Reese, S., H.-J. Markau and H. Sterr (2003). MERK - Mikroskalige Evaluation der Risiken in überflutungsgefährdeten Küstenniederungen, Forschungs- und Technologiezentrum Westküste, Büsum, Germany.

30. Samela, C., S. Persiano, S. Bagli, V. Luzzi, P. Mazzoli, J. Mysiak and A. Castellarin (2020). Raster-based model for pluvial hazard assessment in urban areas: Hierarchical Filling-\&-Spilling. 4th European Conference on Flood Risk Management, Budapest, Hungary, submitted.

31. Samela, C., T. J. Troy, S. Manfreda (2017). Geomorphic classifiers for flood-prone areas delineation for data-scarce environments. Advances in Water Resources 102, 13-28.

32. Schröter, K., H. Kreibich, K. Vogel, C. Riggelsen, F. Scherbaum and B. Merz (2014). How useful are complex flood damage models?. Water Resources Research 50(4): 3378-3395.

33. Thieken, A. H., A. Olschewski, H. Kreibich, S. Kobsch and B. Merz (2008). Development and evaluation of FLEMOps - a new Flood Loss Estimation MOdel for the private sector. In: D. Proverbs, C. A. Brebbia \& E. Penning-Roswell (Eds.), Flood Recovery, Innovation and Response Vol. 118, WIT Press, pp. 315-324.

34. Thieken, A. H., M. Müller, H. Kreibich and B. Merz (2005). Flood damage and influencing factors: New insights from the August 2002 flood in Germany. Water Resources Research 41(12): W12430.

35. Vousdoukas, M. I., L. Mentaschi, E. Voukouvalas, M. Verlaan, S. Jevrejeva, L. P. Jackson, L. Feyen (2018). Global probabilistic projections of extreme sea levels show intensification of coastal flood hazard. Nature Communications 9: 2360.

36. Vousdoukas, M. I., L. Mentaschi, L. Feyen and E. Voukouvalas (2017). Extreme sea levels on the rise along Europe's coasts. Earth's Future 5: 304-323. 
Budapest University of Technology and Economics (BME)

37. Wagenaar, D., J. de Jong and L. M. Bouwer (2017). Multi-variable flood damage modelling with limited data using supervised learning approaches. Natural Hazards and Earth System Sciences 17: 1683-1696. 